\title{
Von den Steinen zu den Menschen. Vorwort des Herausgebers
}

Die Ursprünge des vorliegenden Bandes reichen weit zurück. Im Wintersemester 2002/ 03 - am Institut für Geschichte der Martin-Luther-Universität Halle existierte noch der Studiengang Historische Hilfswissenschaften - veranstaltete ich zunächst eine Vorlesung, die die Studierenden in die Methodik der Inschriftenkunde einführte, und im darauf folgenden Sommer ein Seminar samt Übung, das sich der Epigraphik von der praktischen Seite nähern sollte. Als exemplarisches Betätigungsfeld bot sich der Stadtgottesacker in Halle an, mit seiner Kombination aus Bauinschriften und Grabdenkmälern eines der bedeutendsten Ensembles dieser Art in Deutschland. Eine Gruppe interessierter Studenten fand sich, allwöchentlich im Seminar und auf dem Gottesacker, um zunächst ein Aufnahmeschema zu erarbeiten und dieses dann - getrennt in Gruppen von zwei bis drei Forschern - vor Ort an einzelnen Objekten anzuwenden. Dazu gehörte die Lektüre, Transkription und Übersetzung der Inschriftentexte, die technische Aufnahme durch Vermessung und Fotografie und nicht zuletzt die flankierende Recherche zu den bestatteten Personen, in erster Linie im Stadtarchiv und der Marienbibliothek, wo Ralf Jacob und Anke Fiebiger geduldig bei der Materialsuche halfen. Wertvolle Hilfestellung leisteten auch Helmut Stelzer und Thomas Zaglmaier (Büro für Architektur und Denkmalpflege), in deren Händen die gleichzeitig durchgeführte bauliche Instandsetzung des Komplexes lag, sowie Hartmut Bade vom Grünflächenamt der Stadt, der uns immer wieder in unbürokratischer Weise den Zugang zu den verschlossenen Gruftbögen ermöglichte.

Schon früh erwuchs aus dieser Arbeit der Gedanke an eine Edition. Als besonderer Glücksfall erwies sich, dass die Arbeitsstelle des Projekts der „Deutschen Inschriften“ der Sächsischen Akademie der Wissenschaften ihren Sitz gleich nebenan im Kröllwitzer Institutsgebäude hatte, und dass sich deren Mitarbeiter Hans Fuhrmann und Franz Jäger mit viel Engagement unseres Unternehmens annahmen. Insbesondere letzterer, der zu dieser Zeit selbst den Band „Inschriften der Stadt Halle an der Saale“ vorbereitete, wurde zu einem Stützpfeiler des Projekts. Vor Ort, bei der minutiösen Aufnahmearbeit mit Leuchten und Leitern, demonstrierte er den Studierenden die notwendigen Arbeitsschritte, aber auch die Erkenntnismöglichkeiten, die in diesem Material stecken.

Natürlich sollte unser Buch nicht mit seinem Inschriften-Band kollidieren, der 2012 vorgelegt wurde. Unser Konzept ist ein anderes. Nicht nur der Bearbeitungszeitraum -

Ә Open Access. (C) 2021 Klaus Krüger, publiziert von De Gruyter. (cc) BY-NC-ND Dieses Werk ist lizenziert unter der Creative Commons Attribution-NonCommercial-NoDerivatives 4.0 Lizenz. 
wir haben die anderthalb Jahrhunderte von 1550 bis 1700 im Blick -, sondern auch die Zielgruppe unterschied sich von Beginn an: Um vor Ort als erweiterter Führer dienen zu können, wurde der Band so konzipiert, dass die Reihenfolge der Inschriften nicht chronologisch angelegt ist, sondern der Anlage der Arkatur folgt. Dabei kann jedes erhaltene Objekt - ob Bauinschrift oder Grabdenkmal - durch ein Foto identifiziert werden. Alle dokumentierten Inschriften stehen dem Benutzer in Form von hochauflösenden Bildern zudem durch einen Link ins Internet zur Verfügung. Das Buch kann somit zum einen als Hilfsmittel eingesetzt werden, das die einzelnen Inschriften in Transkription und Übersetzung, mit Erklärungen und weiterführenden Hinweisen versehen, aufbereitet. Zugleich aber soll es ein Beitrag zur Stadtgeschichte der frühen Neuzeit sein, Grundlage für eine Prosopographie des hallischen Bürgertums, zusätzlich ausgestattet mit den Lebensdaten der Bestatteten und weiterer in den Inschriften erwähnten Personen, die deren Identifizierung erlaubt und so weiterführende Forschung - von den Steinen zu den Menschen - ermöglicht. Katrin Moeller (Institut für Geschichte), Michael Ruprecht (Stadtarchiv Leipzig), Andreas Lesser (Friedrich-Christian-Lesser-Stiftung München) und Matthias Meinhardt (Reformationsgeschichtliche Forschungsbibliothek Wittenberg) ist für die Bereitstellung von Material aus ihren je eigenen Forschungsbereichen zu danken.

Eine erhebliche Schwierigkeit ergab sich aus der verwendeten Sprache: Es verstand sich von selbst, dass der Edition Übersetzungen beigefügt werden sollten, aber ein großer Teil der Grabinschriften wurde für (und durch) gelehrte Angehörige der städtischen Eliten gesetzt, die ein besonderes Interesse an klassischer Bildung und humanistischem Gedankengut erkennen lassen. So erwies sich das verwendete Latein teilweise als ausgesprochen komplex in seinem Rückgriff auf antikisierende Formen und Inhalte. Aus diesem Grunde führte ich im Sommer 2005 einen Lektürekurs zu den „Lateinische(n) Inschriften am Stadtgottesacker in Halle“ durch, wodurch weitere Studierende an das Projekt herangezogen wurden. Auch Heike Endermann (damals am Institut für Klassische Altertumskunde) und Ingrid Würth (Institut für Geschichte) brachten wichtige Hinweise bei. Die schwierigsten Übersetzungen blieben indessen lange liegen; ihrer nahmen sich schließlich andere an, und ich danke dafür meinen Freunden Martina Steinkühler (Regensburg) und Reinhard Lamp (Hamburg).

Mehrere Jahre lang, in denen der Herausgeber durch anderes von der kontinuierlichen Arbeit abgehalten wurde und in denen die meisten der einstigen Bearbeiter aus dem Umkreis des Instituts verschwanden, wurde das Projekt - jenseits aller Gedanken an Scheinerwerb oder materiellen Ausgleich - durch einige Hartgesottene auf eigene Initiative vorangetrieben. Im Laufe der Zeit einander ablösend, waren es Bettina SchröderBornkampf, Katja Pürschel und Conny Jakab, die die von den Kommilitonen eingegangenen Texte korrigierten, ergänzten, vereinheitlichten und die notwendigen Verzeichnisse und Register erstellten. Diese drei sind die eigentlichen Bearbeiterinnen der Inschriften, jede von ihnen hat jede Datei irgendwann auf dem Schreibtisch gehabt. Ohne sie würde es das vorliegende Buch nicht geben. Flankiert wurde ihre Arbeit durch die Bemühungen 
anderer Studierender, die ihrerseits je eigene Beiträge leisteten: Die Steinmetzzeichen wurden von Steffen Glöge und Marc-Robert Wistuba blasoniert, die Fotos stammen von Ilja Claus, der im Jahr 2011 zum Projekt hinzugestoßen ist und viele Ideen zu neuen Dokumentationstechniken beigesteuert hat.

Mein abschließender Dank gilt zum einen meiner Frau Birte und meinem Sohn Benno, die durch immer wieder nötige Freistellung des Familienvaters dafür sorgten, dass dieser Band nach vielen Jahren nun endlich erscheinen kann, zum anderen dem Stifter Dietrich Moderhack für finanzielle Unterstützung der Drucklegung. Für die Aufnahme in ihre Schriftenreihe danke ich schließlich den Freunden und Kollegen Andreas Pečar und Andreas Ranft, dem letzteren auch sehr herzlich für die Bereitstellung von Forschungsgeldern seiner Professur. 
